\title{
Test-supported numerical analysis for evaluation of the load capacity of thin-walled corrugated profiles
}

\author{
A. PIEKARCZUK* \\ Instytut Techniki Budowlanej, 1 Filtrowa St. 00-611 Warszawa, Poland
}

\begin{abstract}
The paper concentrates on a quantitative evaluation of the load capacity of thin-walled, curved steel profiles used as arched roofs in building structures. Corrugation of a profile surface formed by cold rolling changes its load capacity as compared to thin-walled profiles. The paper presents a comparative evaluation of the influence of a sample profile corrugation on its ability to transfer internal forces. The results of the study are presented as limit curves describing load capacity at simultaneous bending and compression. The analysis was conducted using a numerical computational method supported by a study of elements in natural scale. The paper presents a methodology of test-supported calculations and guidelines for practical use by designers.
\end{abstract}

Key words: numerical analysis, corrugated thin-walled profiles, tests of thin-walled profiles.

\section{Introduction}

Profiled thin-walled u-shaped profiles, curved to form a circular arch, are used in civil engineering as roof covering for public buildings. Thin-walled profiles are produced in a two-stage process of steel sheet cold-rolling using mobile rolling mills. The first stage of the manufacturing process involves forming a straight linear u-shaped profile of $0.75-1.5 \mathrm{~mm}$ thick steel sheet with shapes and dimensions as presented in Fig. 1. In the second stage, the profile is curved to form a circular arch shape

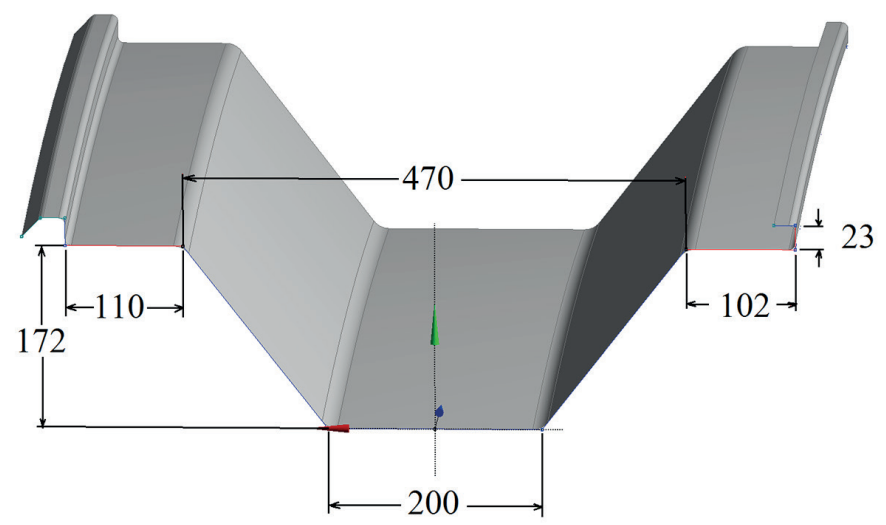

Fig. 1. U-shaped profile after the first stage of rolling

with a radius ranging from $6 \mathrm{~m}$ to $30 \mathrm{~m}$. As a result of the process, a single curved profile with specific transverse corrugated surfaces of webs is formed (Fig. 2). In [1] this type of profile

*e-mail: a.piekarczuk@itb.pl

Manuscript submitted 2017-04-20, revised 2017-06-14, initially accepted for publication 2017-07-26, published in December 2017.

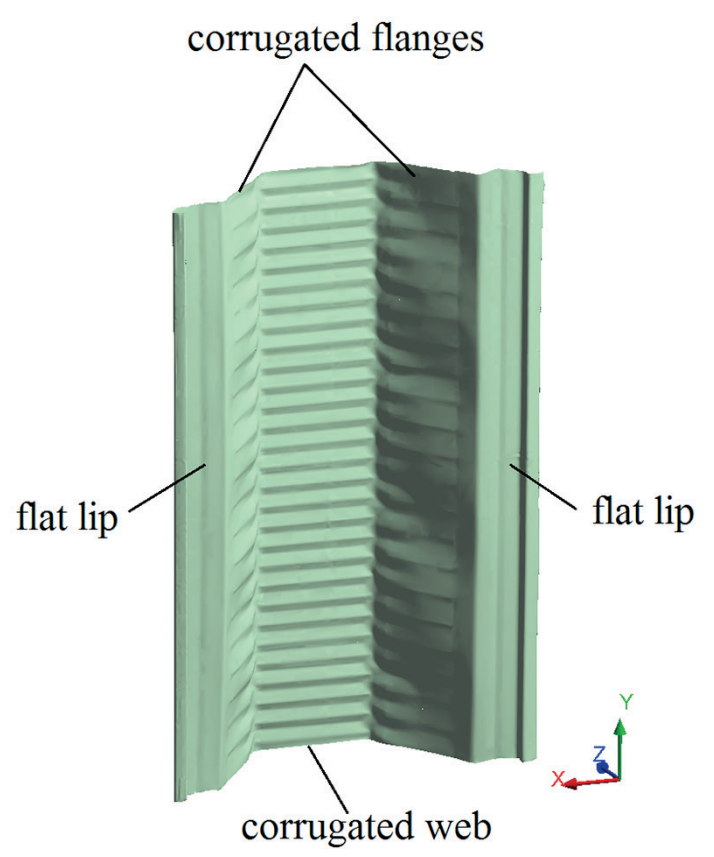

Fig. 2. U-shaped profile after the second stage of rolling

has been qualified as third generation. Single profiles are connected with one another using special locks on the free edges (flat lips). As a result of the combination of single profiles, a continuous trapezoidal surface is formed, which is a self-supporting element with no intermediate supporting construction.

This solution helps to make arched roofs with a span of up to $30 \mathrm{~m}$ and of different elevations. The method owes its popularity to its lower cost and shorter completion time as compared to traditional methods [2]. An arched roof should be designed so that load capacity and stability requirements are met. Unfortunately, there are no coherent methods to design such structures because reference standards do not cover 
profiles with corrugated surfaces. So far, most designs have been based on individual calculation methods, which do not take into consideration the specific shape of a profile surface. Sometimes, this causes failures or the collapse of such structures $[3,4]$. A profile shape is a major problem in the identification of the load capacity and stability of the structure. After forming, corrugation and waviness occur on central surfaces of the profile (Fig. 2). The corrugation geometry of the u-shaped part of a profile mainly depends on the arch bending radius and sheet core thickness [7]. Overpressing on the central surfaces of profiles contributes to a change in their rigidity, compared to profiles with straight walls, and increases the tendency to form local instabilities. The evaluation of the load capacity and rigidity of profiles is difficult, as product ranges can vary in their bending radius and sheet core thickness. Laboratory tests and studies $[5,6]$ revealed that the load capacity and stability of corrugated profiles determine strong non-linearity. It was also highlighted that it is difficult to select an appropriate profile geometry model from numerical calculations. In practice, designers tend to oversimplify computational models using bar or coating elements without surface corrugations. The simplifications generate quality and quantity differences, compared to full-geometry profiles. The paper describes differences in the results of a numerical analysis of the load capacity and rigidity of 3D profile coating models with corrugated surfaces, as compared to profiles with flat surfaces. The analysis was conducted assuming compression with variable eccentricity and bending, and their interactions.

\section{Methodology}

2.1. Geometry of profiles and material model. Two samples of thin-walled profiles were selected for comparative calculations. The first one is a reference model further validated in the study in Section 3.1, which is an accurate representation of the geometry with preserved surface corrugation (Fig. 3a). The corrugation geometry was established based on measurements of a real workpiece. The second model (Fig. 3b) has no corrugated surface and preserves only a curve along the longitudinal a)

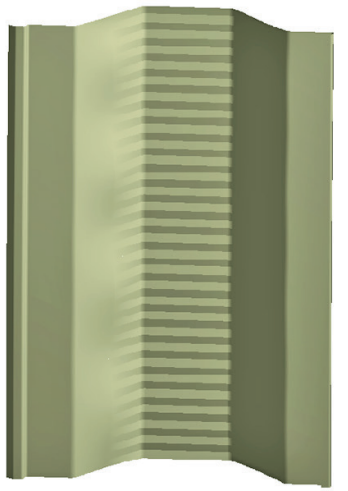

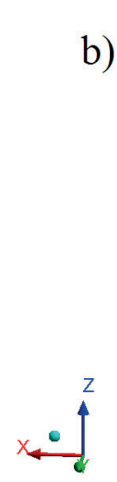

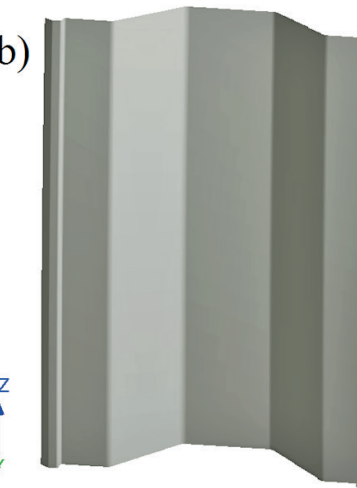

Fig. 3. U-shaped profile, a) version with corrugated surfaces, b) version with flat surfaces axis. Both models are $1.0 \mathrm{~m}$ long and curved lengthwise along an $18 \mathrm{~m}$ radius. The cores of the profiles are made of $1.4 \mathrm{~mm}$ thick steel sheet (nominal thickness).

The corrugated profile length $(1.0 \mathrm{~m})$ was selected based on a buckling analysis. This was identified to be a sufficient length for buckling, as it would not cause any local loss of stability, while obtaining a satisfactory length to reduce the influence of the support on a local loss of stability in the central part of a profile. A multilinear material model with isotropic hardening was used in the calculations [9]. A material model was established based on 10 static elongation tests according to [8]. The test material was collected from a sheet, which was also used to make a test workpiece to validate the computational reference model.

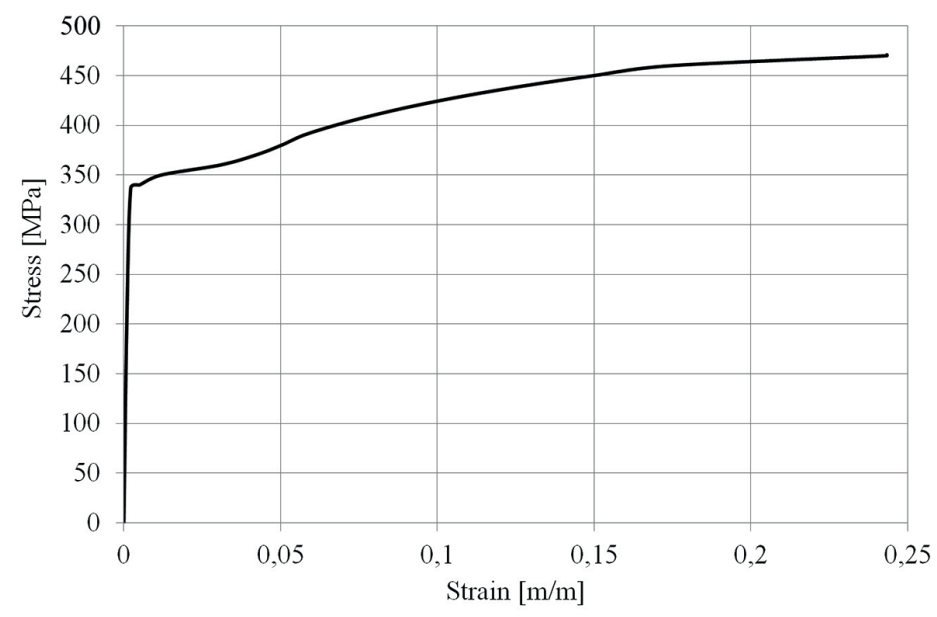

Fig. 4. Material model

An elastic-plastic multilinear material model [9] (Fig. 4) was adopted for numerical calculations using ANSYS. The model describes the relationship between the $\sigma_{\text {true }}$ and $\varepsilon_{\ln }$ variables, according to the following formula:

$$
\begin{gathered}
\varepsilon_{\ln }=\int_{1_{0}}^{1} \frac{\mathrm{dl}}{1}=\ln \left(\frac{1}{1_{0}}\right)=\ln \left(\frac{1_{0}+\Delta \mathrm{l}}{1_{0}}\right)=\ln \left(1+\varepsilon_{\text {eng }}\right) \\
\sigma_{\text {true }}=\sigma_{\text {eng }}\left(1+\varepsilon_{\text {eng }}\right)
\end{gathered}
$$

where:

$\varepsilon_{\mathrm{ln}}-$ relative logarithmic strain,

$\sigma_{\text {true }}-$ actual stress,

$\sigma_{\text {eng }}-$ engineering stress (test result),

$\varepsilon_{\text {eng }}-$ engineering strain (test result),

$\Delta \mathrm{l}$ - sample length gain [mm],

$1_{0}-$ initial sample length [mm].

The yield point obtained in the tests [8] amounted to $337 \mathrm{MPa}$, while the strength limit was $388 \mathrm{MPa}$. Other material characteristics, such as Young's modulus and Poisson ratio, were considered according to [10]. For simplification, the test data apply only to the mean value and do not include complex phenomena related to measurement uncertainty [11]. 
2.2. Finite element mesh selection. Shell 181 type of coating elements [9] from ANSYS were used in both computational models. The relevance of the calculation results for the application of a mesh with Shell 181 element types, compared to exact methods, was confirmed in [12]. The mesh quality is assumed to be satisfactory if the netting parameters' concentration does not exceed 5\% [13], in reference to a result obtained during calculations for a model with a looser mesh. The FE mesh dimensions (max/min) were reduced by about $60 \%$ compared to a mesh with standard ANSYS parameters (automatically generated). The load capacity of a workpiece under axial compression was taken for the tests. Studies of concentrated FE mesh revealed that the standard settings of ANSYS meshing are sufficient to obtain acceptable results. The modification of the netting dimensions by $60 \%$ caused a change in the result (load capacity) by $0.4 \%$ for a corrugated workpiece, and by $2.9 \%$ for a flat workpiece.

Table 1

Evaluation of FE mesh

\begin{tabular}{|l|c|c|c|}
\hline \multicolumn{1}{|c|}{ model } & $\begin{array}{c}\text { Mesh parameters } \\
(\min / \max )[\mathrm{mm}]\end{array}$ & $\begin{array}{c}\text { Number of } \\
\mathrm{FE}\end{array}$ & $\begin{array}{c}\text { Load capacity } \\
{[\mathrm{kN}]}\end{array}$ \\
\hline \multirow{2}{*}{ flat } & $2.8 / 13.3$ & 15.691 & 103.265 \\
\cline { 2 - 4 } & $1.7 / 7.0$ & 25.988 & 100.327 \\
\hline \multirow{2}{*}{ corrugated } & $1.6 / 8.1$ & 32.147 & 81.763 \\
\cline { 2 - 4 } & $1.0 / 5.0$ & 52.588 & 81.416 \\
\hline
\end{tabular}

The results are quite below the established upper acceptance criteria. Mesh concentration does not improve the results significantly but increases the time necessary to obtain them. Standard ANSYS netting was followed in the calculations.

2.3. FE boundary condition and calculation methods. Support conditions are presented in Fig. 5. The lower support can rotate only around the $X$ axis $\left(\varphi_{X 1} \neq 0\right)$. Other degrees of freedom were eliminated $\left(\varphi_{\mathrm{Y} 1}=0, \varphi_{\mathrm{Z} 1}=0, \delta_{\mathrm{X} 1}=0, \delta_{\mathrm{Y} 1}=0, \delta_{\mathrm{Z} 1}=0\right)$. The upper support can rotate around the $Z$ axis $\left(\varphi_{X 2} \neq 0\right)$ and move along the $\mathrm{Y}$ axis $\left(\delta_{\mathrm{Y} 2} \neq 0\right)$. Other degrees of freedom were eliminated $\left(\varphi_{\mathrm{Y} 2}=0, \varphi_{\mathrm{Z} 2}=0, \delta_{\mathrm{X} 2}=0, \delta_{\mathrm{Z} 2}=0\right)$. The supports were provided by a rigid body.

Loading was applied in the calculations by displacement or rotation of the supports. Three independent loading sequences were planned for the calculations. The first sequence took into consideration eccentric compression with a positive eccentricity (web compression), the second sequence involved compression with a negative eccentricity (web tensioning), while the third sequence examined bending with no axial force. Displacement $\delta Y 2(0)$ (Fig. 6a) is located in the neutral axial of inertia and creates axial compression. The displacements in the first and second sequence $\delta_{\mathrm{Y} 2}(+)$ and $\delta_{\mathrm{Y} 2}(-)$ are moved against the inertia axis on eccentricity $\mathrm{e}(+)$ or $\mathrm{e}(-)$ respectively, with the following values: $30 \mathrm{~mm}$; $60 \mathrm{~mm} ; 90 \mathrm{~mm} ; 105 \mathrm{~mm}$ and $120 \mathrm{~mm}$. The calculations assumed that the bottom edge supporting point for each eccentricity was in the displacement axis. Such an arrangement ensures eccentric compression without additional torsion.

Pure bending in two directions $\mathrm{M}(+)$ and $\mathrm{M}(-)$ (Fig. 6b), with no participation of axial and torsional forces, was con-

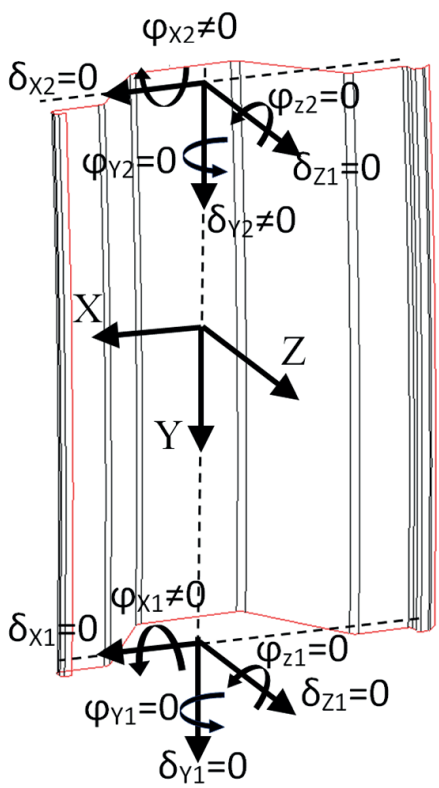

Fig. 5. Support conditions a)

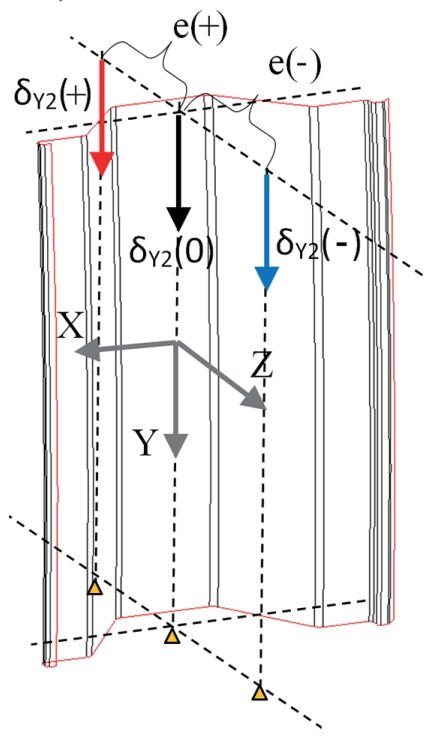

b)

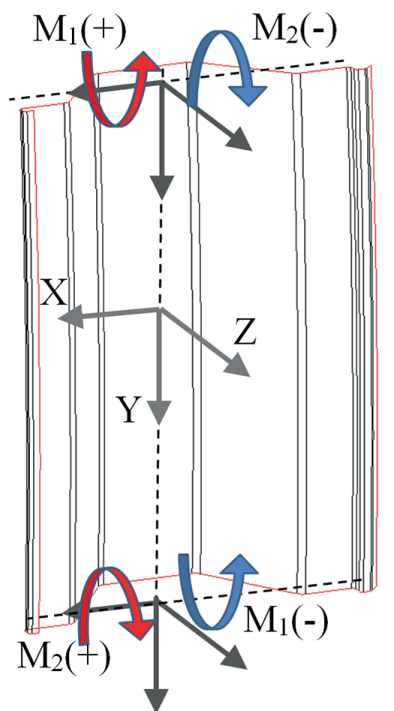

c)

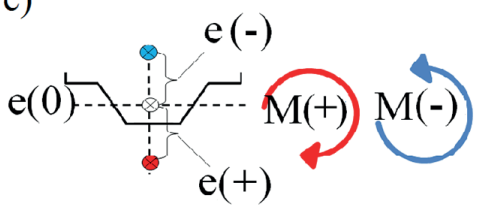

Fig. 6. Loading method a) eccentric compression, b) bending, c) draft presentation of the action of eccentric forces and bending moments

sidered in the third sequence. Non-linear calculations used the Arc-Length [14] method, which facilitated an analysis in the full load range to find the non-destructive load and also monitor the post-critical balance path. The calculations were conducted by kinematic extortion applied at the top support. 


\section{Calculations}

3.1. Reference model validation. Validation was presented as an evaluation of the uncertainty of numerical simulations [15] by means of data from experimental formulas. Such an approach requires an independent estimation of the errors and uncertainty of experimental and numerical data. A comparison error $(\mathrm{E})$ is defined as a difference between the values obtained in tests (D) and in numerical calculations (S).

$$
\mathrm{E}=\mathrm{D}-\mathrm{S}
$$

Validation uncertainty is identified based on the following relationship:

$$
\mathrm{U}_{\mathrm{V}}^{2}=\mathrm{U}_{\mathrm{D}}^{2}+\mathrm{U}_{\mathrm{SPD}}^{2}+\mathrm{U}_{\mathrm{SN}}^{2}
$$

where:

$\mathrm{U}_{\mathrm{SN}}$ - uncertainty in numerical simulation,

$\mathrm{U}_{\mathrm{SPD}}$ - uncertainty of material input data,

$\mathrm{U}_{\mathrm{D}}$ - uncertainty of experimental data.

Validation is achieved when comparison error $(\mathrm{E})$ is lower than validation uncertainty $\left(\mathrm{U}_{\mathrm{V}}\right)$

$$
|\mathrm{E}|<\mathrm{D}_{\mathrm{V}} \text {. }
$$

An expression described by relationship (5) is a process validation metric.

The test method description and implementation are described in detail in [6]. In the reference case, the tested profile had a bending radius of $18 \mathrm{~m}$ and nominal core thickness of $1.4 \mathrm{~mm}$. The test was performed at axial compression, negative eccentricity $\mathrm{e}=-105 \mathrm{~mm}$ and positive eccentricity $\mathrm{e}=+105 \mathrm{~mm}$ (Fig. 6a). The test was continued until evident strain was achieved after the destruction of the workpiece. A balance path in the force - axial displacement $\delta_{\mathrm{Y} 2}$ arrangement (Fig. 5) is the test result. The peak values of forces obtained in the tests and calculations were used for validation purposes, as they will be used further in calculations for building the limit curve of the bending moment - compression force. Calculations were made for the same support conditions as in the test, while maintaining the profile geometry obtained based on the profile measurements in a natural scale and maintaining the support and load conditions described in Section 2.3.

Figure 7 presents a comparison of the results of tests and calculations. The maximum load values from calculations are very similar to the test results. Comparison errors for the peak load values for eccentricity $\mathrm{e}=0 \mathrm{~mm}$ and $\mathrm{e}=+105 \mathrm{~mm}$ do not exceed $\mathrm{E}=0.4 \%$. For compression with eccentricity $\mathrm{e}=-105 \mathrm{~mm}$, the comparison error amounts to $\mathrm{E}=8 \%$.

Numerical simulation uncertainty for the corrugated model identified in Section 2.2. is $\mathrm{U}_{\mathrm{SN}}=0.4 \%$. Experimental data uncertainty in the peak force load range is $\mathrm{U}_{\mathrm{D}}=10 \%$. Uncertainty of force identification is significant and depends on the load implementation method (arrangement of supports and measurement equipment). The uncertainty of material data (data from 10 tests) is $\mathrm{U}_{\mathrm{SPD}}=3 \%$, following the Welch-Satterthwaite equation [10]. The $\mathrm{U}_{\mathrm{SN}}, \mathrm{U}_{\mathrm{D}}$ and $\mathrm{U}_{\mathrm{SPD}}$ uncertainties are estimated values, and they were considered to be sufficient for the analysis.

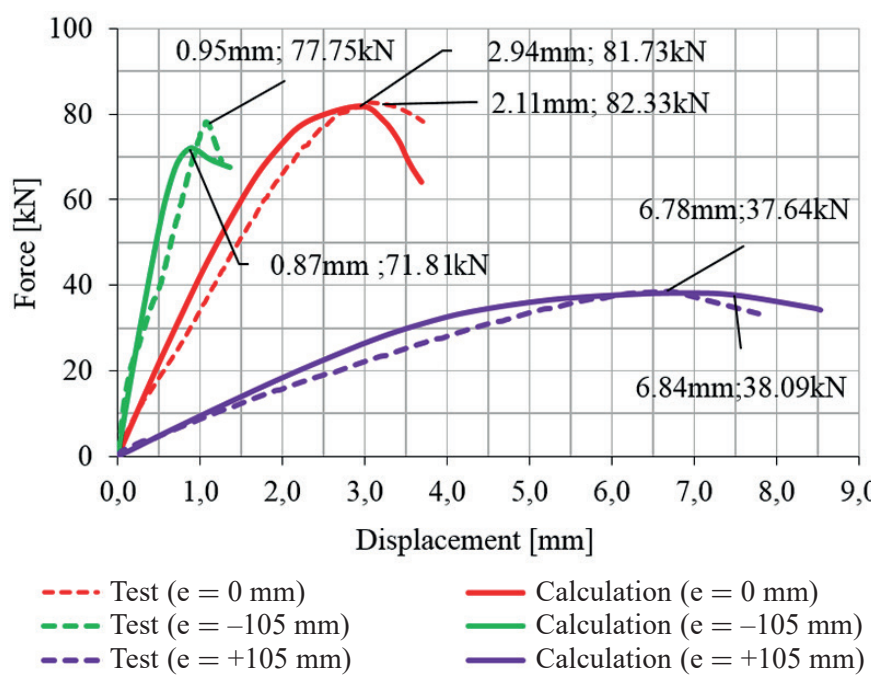

Fig. 7. Comparison of test results and reference model calculations (a)
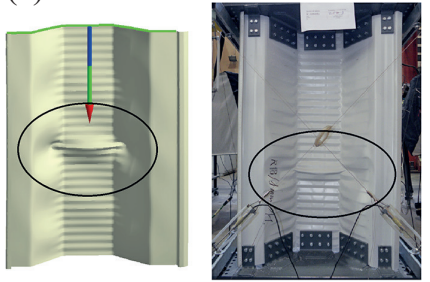

(c)

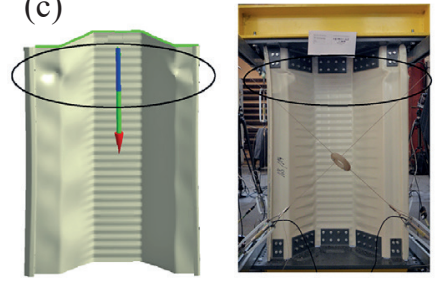

Fig. 8. Workpiece strain. Results of calculation and tests, a) eccentricity $\mathrm{e}=0 \mathrm{~mm}, \mathrm{~b}$ ) eccentricity $\mathrm{e}=+105 \mathrm{~mm}, \mathrm{c}$ ) eccentricity $\mathrm{e}=-105 \mathrm{~mm}$

Considering all components, the process validation metric for the most deviating result (eccentricity $\mathrm{e}=-105 \mathrm{~mm}$ ) is: $\mathrm{E}=8 \%<\mathrm{U}_{\mathrm{V}}=10.4 \%$.

Meeting the process validation criterion for the most divergent result for the peak load value based on tests and calculations confirms that the calculation model is correct. The error is higher for displacements but the parameter does not affect further scope of analysis.

The balance path obtained in tests progresses in a fairly different way than the one obtained in calculations. It is caused by idealisation of the support conditions assumed in the computational model. The fixing in the tests consisted of a set of screw-mounted holders. A system of supports with rigid body characteristics was applied in the calculations.

The forms of failures obtained in the calculations and tests are presented in Fig. 8. The location and nature of failures based on tests and calculations (marked in Fig. 8) are similar (with minor displacement), which is evidence that qualitative confir- 
mation was obtained in addition to the quantitative compliance of the results.

Based on a comparison of the calculation results with the test results it was discovered that the model FE applied in calculations was correct and can be used for further calculations.

3.2. Load and displacement characteristics. Calculations were made for the reference (corrugated) and simplified (flat) model. Balance paths were identified for both models and the procedure was performed for varying eccentricity and, additionally, for pure bending. The support and loading conditions, as well as calculation method for both models were according to Section 2.3.

Figure 9 presents the force - displacement relationship for a corrugated model, while Fig. 10 for a flat one at variable eccentricity of the compressive force. Figure 9 shows the influence of web grooving. This is evidenced by the fact that the maximum values of compressive strength occur at positive eccentricity, i.e. the compressive force reaches its maximum in a position closer to non-corrugated lips (flat lip - Fig. 2). In this case, eccentricity e $=+30 \mathrm{~mm}$.

The situation is different for a non-corrugated profile (Fig. 10). The maximum value of the compression force for this model is achieved at eccentricity e $=0 \mathrm{~mm}$, which corresponds to the inertia axis position. The force-displacement relationship of the corrugated (Fig. 9) and non-corrugated (Fig. 10) profiles has a different layout. In the corrugated profile the loads increase until they reach peak value, which is followed by a loss of stability. In the force - displacement relationship of the non-corrugated profile disturbances occur in some cases, e.g. at the eccentricity values of $\mathrm{e}=-30 \mathrm{~mm}$ and $\mathrm{e}=-90 \mathrm{~mm}$. The load goes up to a certain value, drops and then recovers until load capacity is lost. This is caused by the formation of local plastic buckling, which is low enough for a stable system to gain a secondary load capacity.

A similar, but less intense phenomenon has been observed in [1] during a test concerning resistance to compression of a trapezoidal steel sheet.

The most evident difference between the two types of profiles is axial displacement at the peak load values. In the corrugated model they are two times higher than in the flat model, which means that the lengthwise rigidity of corrugated profiles is significantly lower. There are also differences in the stress distribution on the surfaces of the profiles.

Figure 11 presents maps of reduced stresses at the peak load values (Fmax) and selected eccentricity values e $=0$, $\mathrm{e}=-105 \mathrm{~mm}$ and $\mathrm{e}=+105 \mathrm{~mm}$. Differences in the stress distribution on the surfaces of the compared profiles can be

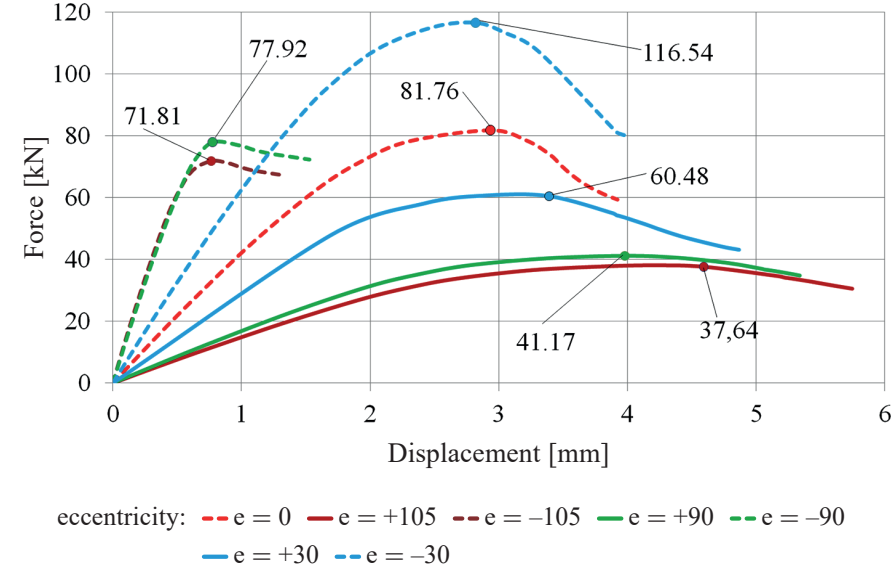

Fig. 9. Comparison of calculation results. Corrugated profile

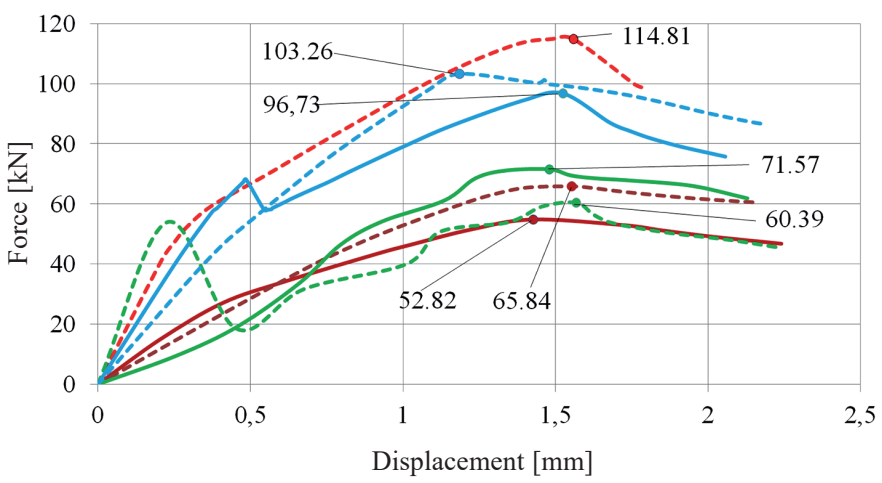

eccentricity: $\begin{aligned}--\mathrm{e} & =0-\mathrm{e}=+105 \quad--\mathrm{e}=-105 \quad-\mathrm{e}=+90 \quad--\mathrm{e}=-90 \\ -\mathrm{e} & =+30--\mathrm{e}=-30\end{aligned}$

Fig. 10. Comparison of calculation results. Flat profile a)

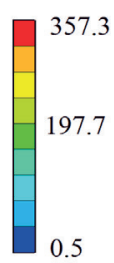

c)

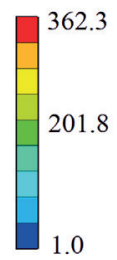

e)

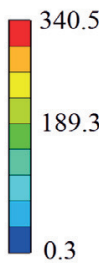

0.3

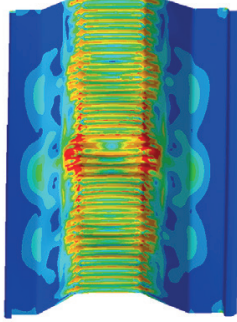

Fmax $=71.81 \mathrm{kN}$

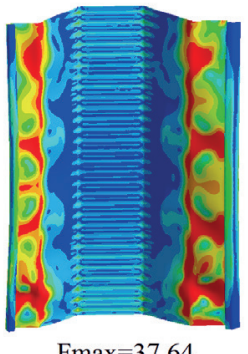

f)

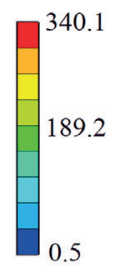

Fig. 11. Comparison of calculation results for reduced stresses in a corrugated and flat profile a) corrugated profile $e=0 \mathrm{~mm}, \mathrm{~b}$ ) flat profile $\mathrm{e}=0 \mathrm{~mm}, \mathrm{c}$ ) corrugated profile $\mathrm{e}=-105 \mathrm{~mm}, \mathrm{~d}$ ) flat profile $\mathrm{e}=-105 \mathrm{~mm}$,

e) corrugated profile $\mathrm{e}=+105 \mathrm{~mm}$, f) flat profile $\mathrm{e}=+105 \mathrm{~mm}$ 
(a)

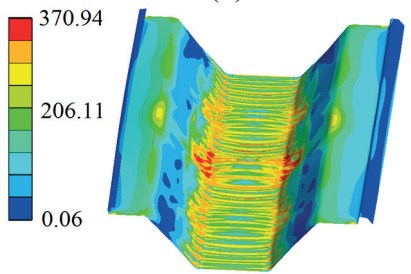

$\operatorname{Mmax}(+)=10.63 \mathrm{kN}$

(c)

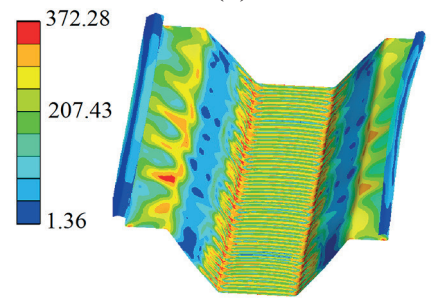

$\operatorname{Mmax}(-)=6.54 \mathrm{kN}$ (b)
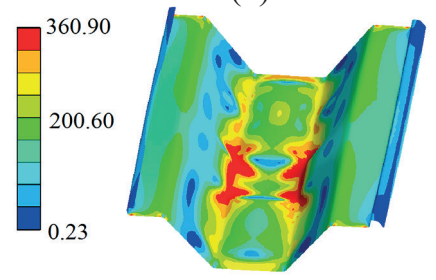

$\operatorname{Mmax}(+)=12.21 \mathrm{kN}$

(d)
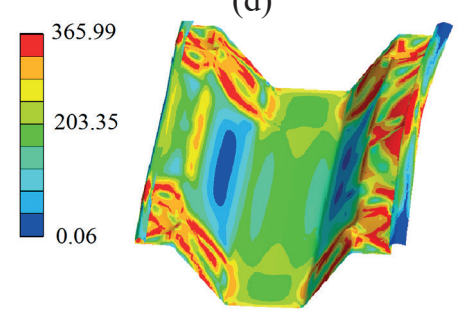

$\operatorname{Mmax}(-)=8.56 \mathrm{kN}$
Fig. 12. Comparison of calculation results of reduced stresses at pure bending a) corrugated profile $\mathrm{M}(+)$, b) flat profile $(\mathrm{M}+)$, c) corrugated profile $\mathrm{M}(-), \mathrm{d})$ flat profile $\mathrm{M}(-)$

observed. The differences are of qualitative and quantitative nature for selected comparison parameters. The peak load values greatly differ from one another, and the maximum stress zones are located in different areas on the profile surface.

Further calculations were performed for loading with a bending moment with no participation of lengthwise forces, according to the diagram presented in Fig. 6b. In this case, only the limit value of the bending moment was examined and the balance path was not checked. The results of the calculations for the two models of profiles are presented in Fig. 12.

Bending moments at which a loss of stability was observed amounted to the following values respectively: for the corrugated profile $\mathrm{M}(+)=10.63 \mathrm{kNm}$ and $\mathrm{M}(-)=6.54 \mathrm{kNm}$, and for the flat profile $\mathrm{M}(+)=12.21 \mathrm{kNm}$ and $\mathrm{M}(-)=8.56 \mathrm{kNm}$. The bending strength of the flat profile is higher by $15 \%$ in the positive direction (corrugated web compression) and by $30 \%$ in the negative direction (corrugated web tensioning) in reference to the corrugated profile. Similarly to compression, there are quality and quantity differences in bending strength.

\section{Results}

Based on the results of load capacity calculations at axial and eccentric compression, and at bending of flat and corrugated profiles without compression, limit curves were developed in a bending moment - compression force $(\mathrm{M}-\mathrm{F})$ arrangement. The limit curve applies to the values of compressive forces and bending moments identified on the basis of calculations. Figure 13 presents a graphic interpretation of the limit curves. Tensile forces were not taken into consideration because such cases do not occur in the construction of arched halls. Shear forces were also ignored for simplification purposes.

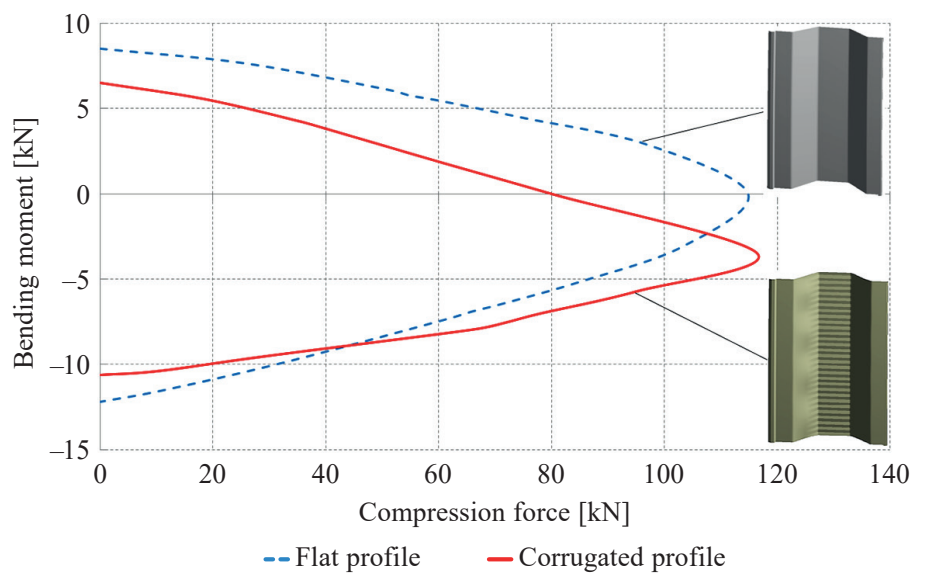

Fig. 13. Bending moment - compression force limit curves

The limit curve of the corrugated profile clearly deviates from the flat profile curve. Extreme values of compression forces are almost identical but they occur at different values of bending moments. The greatest differences are located in the area of positive bending moments (corrugated web compression). In this area, the load transfer capacity of the corrugated profile is much lower. For instance, for the bending moment value of $\mathrm{M}=5 \mathrm{kNm}$, the corrugated profile can transfer a maximum compression force of $25 \mathrm{kN}$, while for the same bending moment value the flat profile transfers a force of $67 \mathrm{kN}$. The point of equal value for both limit curves is located in the area of the negative bending moment (flat lip compression) with the value of $-8.8 \mathrm{kNm}$ at the compression force of $45 \mathrm{kN}$. In addition to the compression force - bending moment relationship, limit curves were developed describing the capacity of a profile to transfer compression force depending on the eccentricity value. Figure 14 presents the results of calculations for flat and corrugated profiles. The eccentricity value of $\mathrm{e}=0$ means that the compression force is located at the point identified by two central inertia axes, plotted in an elastic condition. For the flat profile, the peak load value is

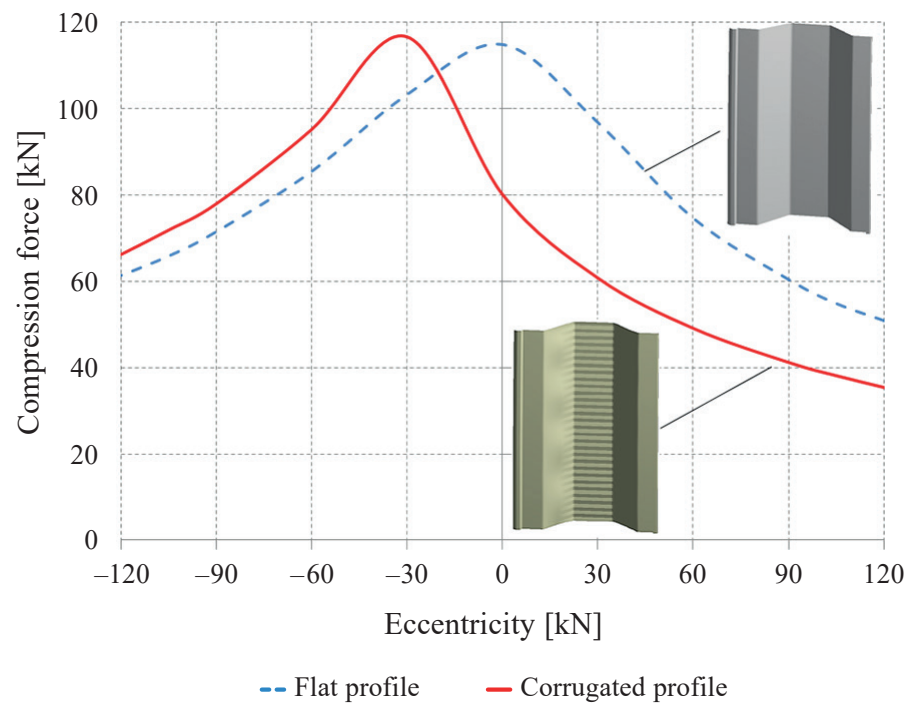

Fig. 14. Bending moment - eccentricity limit curves 
situated in axis e $=0$, while the corrugated profile axis is moved by e $=-30 \mathrm{~mm}$ towards the flat lip (Fig. 2).

The ability of the corrugated profile to transfer compression forces greatly decreases as the eccentricity changes in the positive direction. The nature of the curve descending in this range is much more non-linear than for the flat profile.

\section{Discussion}

Cylindrical roofs are subject to complex loads produced by their own weight, snow and wind [16]. Load standards are used for engineering purposes [17-19]. A relevant set of load combinations causes the formation of a complex of internal forces, where compression forces and different bending moments occur simultaneously. Figure 15 presents a typical load distribution arrangement in the following combination: self-weight, wind, snow and the corresponding distribution of internal forces for a sample $18 \mathrm{~m}$ (span) per $7 \mathrm{~m}$ (elevation) roof. For simplification purposes, only load distributions and diagrams of internal forces are presented, without numerical values. Compression forces (Fig. 15c) have a continuously increasing value towards the supports, while the bending moments occur on both sides of the profile's lengthwise axis (positive and negative values).

In designing such types of structures, some designers use simplified beam models assuming that the rigidity of a profile is fixed, and that load capacity can be checked by analysing

a) suction

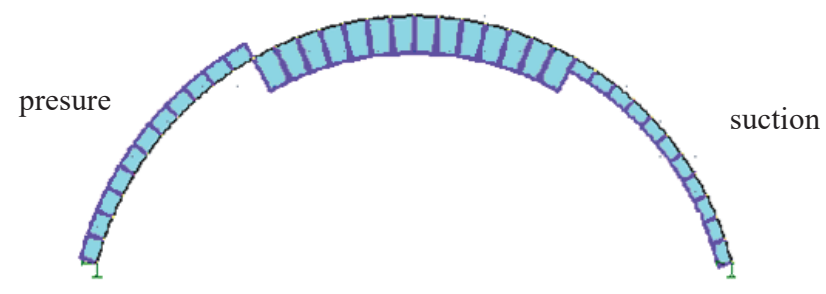

b)
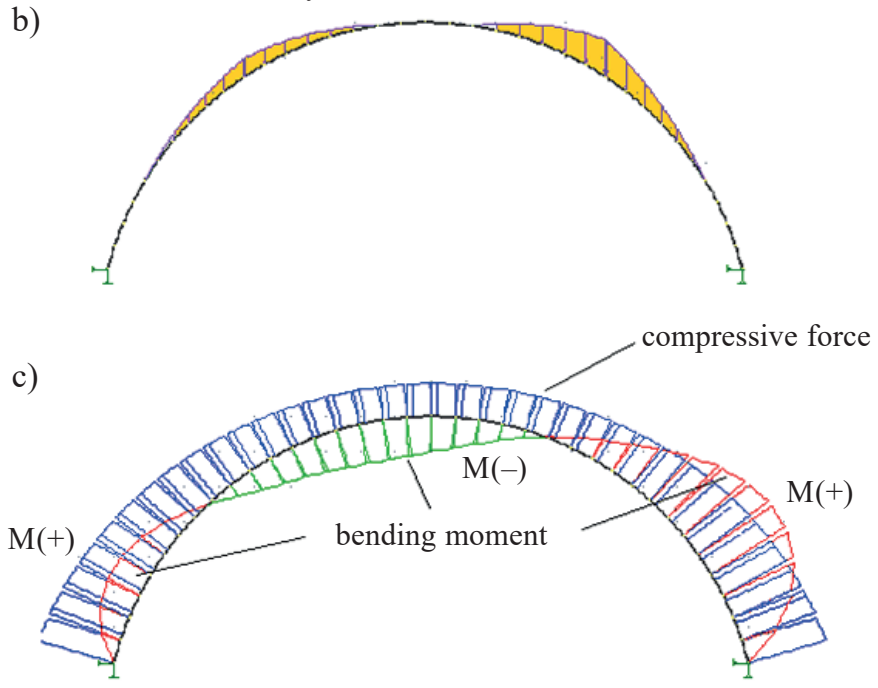

Fig. 15. Arched roof load and graphs of internal forces a) wind load [16], b) snow load [17] - option II, c) graphs of internal forces the most stressed spot (the maximum bending moment and its accompanying lengthwise force). The first simplification carries a risk of error because bar models do not take into consideration profile surface corrugation and the related possibility of local instability. Moreover, the analysis uses an elastic material model, which does not consider plastic effects. The literature mentions specific beam models [20], where a non-linear model with an orthotropic influence effect was used for load capacity evaluation. The orthotrophy was caused by crosswise profile corrugation but its practical application is fairly problematic due to a complicated analytical approach. That is why it seems reasonable to replace beam models with $3 \mathrm{D}$ coating ones. The results of the calculations presented in Section 4 show that this does not guarantee a correct solution either because the flat coating (non-corrugated) model's characteristics in some action ranges of the bending moment and compressive force differ from the characteristics of the corrugated coating model both in quality and quantity.

Another simplification applied by designers is quite trivial but the author has come across it in his practice. It does not suffice to check only the most stressed point of a structure in order to evaluate its load capacity. It is shown in Section 4 that the corrugated profile has different characteristics depending on the orientation of internal forces. Figure 13 shows that the limit curves under the influence of positive and negative bending moments and the simultaneous action of a compression force are not symmetrical against the central inertia axis (eccentricity $\mathrm{e}=0$ ) for corrugated coating profiles. This is a result of web corrugation. Load capacity should then be checked for each extreme arrangement of internal forces, for positive and negative bending moments and taking into account the compressive force.

During the design process, one should also control when and where local plastic buckling may occur as a result of the local loss of stability of a profile. This is of special importance for an analysis of the possible failed condition of a structure. As shown in Section 3.2, a qualitative and quantitative analysis of a flat (non-corrugated) profile yields inaccurate results.

\section{Conclusions}

Formed, arched steel profiles are used as arched roof covering elements in public buildings owing to their easy production and installation, and relatively low cost. Profiles formed by mobile rolling mills have U-shape and corrugated web surfaces. Corrugation of the surface greatly affects the load capacity characteristics of a profile, as compared to a profile with the same cross-section dimensions but with flat surfaces. With regard to the analysis presented in this paper it can be stated that surface corrugation reduces the load capacity of a profile. The ability to transfer the maximum compressive force is almost identical for both corrugated and flat profiles but they occur at different force action eccentricity (Fig. 14). As the bending moment increases, the ability to transfer compression force drops dramatically for the corrugated profile, as compared to the flat one (limit curves - Fig. 15). A quality difference in the location of the most stressed areas on the profile surfaces (Fig. 11) can be 
observed as well. The qualitative difference in the location of the most stressed areas determines the location of a local stability loss, which contributes to a proper evaluation of the load capacity of the whole structure.

Designing arched roofs based on bar models suffers from inaccuracies due to oversimplification. That is why this method can only be applied for a rough estimation of the load capacity of a structure but should not be used for dimensional optimisation. Coating models reflect an actual construction operation in a much better way but it is the accuracy of the numerical models which is of great importance in this case. Neglecting such details of geometry as the corrugation of webs while developing a profile model causes inaccuracies, which may result in design errors.

The author of this paper has demonstrated that corrugated profiles have a specific load capacity nature. This can be detected with advanced numerical calculations but even the most precise calculations do not always give satisfactory results. The most certain way to confirm the correctness of the calculations is to compare them with the results of laboratory tests

This paper has presented such a comparison for a selected reference model of a corrugated profile. The reference model was used further to plot a limit curve in a compressive force bending moment arrangement. Based on the reference model, calculations were made for a non-corrugated profile model, and the differences which can occur when following such simplifications were demonstrated.

At present, the Building Research Institute is conducting work under a research programme aimed at determining the load capacity of corrugated profiles for variable parameters of profile sheet core thickness and different bending radii.

A numerical shell model without corrugation shows significant discrepancies in calculation results in comparison with a model that takes into account the geometry of corrugations. These discrepancies are of both qualitative and quantitative nature. The main purpose of the paper is to show designers that modelling with simplified geometry should not be used in static calculations for such structures. Further research will be focused on the utilisation of the numerical shell model with corrugations for the purpose of preparing a simplified FEM calculation model. This model will be based on simple to use, non-linear beam superelements, that would be easily adaptable to the engineering method of calculations.

Acknowledgements. The financial support from National Centre for Research and Development within the project OPT4BLACH (PBS1/A2/9/2012) is gratefully acknowledged.

\section{REFERENCES}

[1] A. Biegus. Load bearing capacity of corrugated scheets under compression, pp.7-8. Wydaw. Politech. (1983). [in Polish].

[2] R. Walentyński, K. Kozieł, M. Olszowski, and R. Cybulski, "Double corrugated roofs versus traditional solutions - economic analysis" ("Dachy łukowe podwójnie gięte a rozwiązania tradycyjne - analiza ekonomiczna"). Nowoczesne hale, 4 (13), 12-14 (2013). [in Polish].
[3] A. Biegus and A. Kowal, Collapse of a barrel vault hall made from cold-formed scheels. XXV-th Conference of Structural Failures. Międzyzdroje. West Pomeranian University of Technology Szczecin. 766-772, (2011), [in Polish].

[4] A. Biegus and A. Kowal. "Collapse of halls made from coldformed steel sheets." Engineering Failure Analysis 31, 189-194, (2013). http://dx.doi.org/10.1016/j.engfailanal.2012.12.009

[5] A. Piekarczuk, K. Malowany, P. Więch, M. Kujawińska, and P. Sulik, "Stability and bearing capacity of arch-shaped corrugated shell elements: experimental and numerical study", Bull. Pol. Ac.: Tech. 63 (1), 113-123 (2015), ISSN (Online) 2300-1917, DOI: 10.1515/bpasts-2015-0013.

[6] A. Piekarczuk and K. Malowany. "Comparative analysis of numerical models of arch-shaped steel sheet sections". Archives of Civil and Mechanical Engineering. 16 (4) , 645-658 (2016).

[7] B. Shirani Bidabadi, H. Moslemi Naeini, M. Salmani Tehrani, and H. Barghikar. „Experimental and numerical study of bowing defects in cold roll-formed, U-channel sections". Journal of Constructional Steel Research. 118, 243-253, 2016). http://dx.doi.org/10.1016/j.jcsr.2015.11.007

[8] EN ISO 6892-1:2009, "Metallic materials. Tensile testing - Part 1: Method of test at room temperature".

[9] P. Kohnke. Theory Reference for the Mechanical APDL and Mechanical Applications, Ansys Inc. USA, (2009).

[10] EN 1993-1-1:2006. "Eurocode 3: Design of steel structures - Part 1-1: General rules and rules for buildings".

[11] E. Szewczak and A. Piekarczuk. Performance evaluation of the construction products as a research challenge. Small error - big difference in assessment? Bull. Pol. Ac.: Tech. 64 (4), 675-686 (2016), ISSN (Online) 2300-1917, DOI: 10.1515/ bpasts-2016-0077.

[12] K. Liew, L. Peng, and S. Kitipornchai. "Nonlinear analysis of corrugated plates using a FSDT and a meshfree method". Computer Methods in Applied Mechanics and Engineering (196), 2358-2376, (2007). doi:10.1016/j.cma.2006.11.018

[13] M. Kotełko, Load-bearing capacity and the mechanisms of failure of thin-walled structures, pp. 72-75, Wydawnictwa Naukowo-Techniczne, Warszawa, (2011), [in Polish].

[14] B. Forde and S. Steimer. Improved arc length orthogonality methods for nonlinear finite element analysis. Computers \& Structures. 27, (5), 625-630 (1987), doi:10.1016/0045-7949(87)9007 $8-2$

[15] F. Stern, et al. "Comprehensive approach to verification and validation of CFD simulations-part 1: methodology and procedures." Journal of fluids engineering 123 (4) 793-802 (2001). DOI: $10.1115 / 1.1412235$

[16] E. Narvydas and N. Puodžiūnienè, "A preliminary approach to the load and stress analysis of arc-shaped corrugated steel structure", Mechanika 19 (1),12-18, (2013). doi:10.5755/j01. mech.19.1.3629

[17] EN 1991-1-4:2008/A1:2010. "Eurocode 1: Actions on structures - Part 1-4: General actions - Wind action".

[18] EN 1991-1-3:2005/A1:2015-10 "Eurocode 1: Actions on structures - Part 1-3: General actions - Snow loads".

[19] EN 1990:2002/A1:2005/AC:2010 "Eurocode: Basis of structural design".

[20] J. Zaras, K. Kowal-Michalska, J. Rhodes, and X. Fan. A simplified computation model for arch - shaped corrugated shell roof, Thin-Walled Structures - Advances and Developments Elsevier.109-117(2001) 